\title{
Teaching in an EFL Program in Second Life: Student Teachers' Perspectives and Implications
}

\author{
Charles Xiaoxue Wang \\ Mary L. McDowell Lefaiver \\ Florida Gulf Coast University
}

Qi Wang

Georgia State University

Christy Hunt

Dekalb County School District

\begin{abstract}
Educational researchers have paid considerable attention to the use of multi-user virtual environments (MUVEs) to support learning across curricula. Among those MUVEs, Second Life (SL) is one of the most popular. This paper reports on a study of student teachers' experience of teaching English in an experimental EFL (English as a Foreign Language) program in Second Life (SL) with students in China. This study was a collaborative effort of faculty members and graduate students of both a state university in the USA and a provincial university in China. The study took a case study approach to reveal student teachers' perceptions of their teaching in SL, what they have learned and discusses the implications for teaching in similar EFL programs in SL.
\end{abstract}

Keywords: EFL learning and instruction, Second Life, multi-user virtual environments (MUVEs), student teaching.

\section{Introduction}

Multi-user virtual environments (MUVEs) are relatively new and innovative platforms in which individuals may seek real-life experiences in a world through "exploration, simulation, role-play, interaction and experimentation (Burgess, Slate, Rojas-LeBoeuf, \& LaPrairie, 2009). The use of MUVEs to support learning has increased significantly and warrants further exploration of the application in educational settings. One of the most notable and popular MUVEs to date, Second Life (SL), was created by Linden Research in 2003 and has subsequently grown to reach millions of "resi- dents" providing virtual spaces for virtual university campuses and businesses from around the world.

As relates to EFL learning and instruction, Second Life provides a unique platform for learners to interact with native English speakers offering "opportunities to practice and perform in the language in the ways that the traditional classroom setting does not allow" (Blasing, 2010, p. 96). Further, SL provides a robust environment allowing both students and instructors to address Communication, Culture, Connections, Comparisons and Communities aspects of foreign language learning and 
instruction. These "five C's" are the five components of the National Standards for Foreign Language Education supported by the American Council on the Teaching of Foreign Languages (ACTFL, 2011).

This paper reports student teachers' perceptions and understanding of teaching EFL (English as a Foreign Language) in SL (SL EFL Program). Through analysis of the student teachers' weekly reflection papers and in-depth interviews, the paper reveals their perspectives on teaching EFL in SL with authentic learning tasks and EFL students across the continents in the virtual world. Based on the findings, the paper also discusses the implications for better facilitating EFL learning in SL.

\section{Literature Review}

Visibility and inquiry on the uses of virtual reality or virtual worlds applied to educational settings began to appear in the early 1990s (e.g. Helsel, 1992; Wickens, 1992). Virtual worlds are computer-simulated environments that simulate places either in the real or imaginary worlds. Historically used to describe massively multiplayers online games (MMOGs) such as World of Warcraft, the term has also come to be used interchangeably with "virtual worlds" or "multi-user virtual environments" (MUVEs). As the use of virtual worlds has increased, the term "MUVEs" has expanded to include platforms beyond those specific to gaming. Nonetheless, virtual worlds retain the inherent characteristic of 3D graphics which allow users to interact in a persistent virtual environment via the Internet.

Much support exists for the use of MUVEs within educational settings, and specifically related to use in creating online communities (Riedl, Bronack, \& Tashner, 2005), enhancing the quality and experiences of student learning (Jarmon, Traphagan \& Mayrath, 2008; Squire \& Jenkins, 2004), and providing collaborative environments (Bruckman, 1997; Erlandson, Nelson, Wilhelmina, 2010). Additional benefits of MUVEs may include improved social interactions, access to information, the integration of technology, and collaborative learning (Dillenbourg, Schneider \& Synteta, 2002). As most instructors realize, motivation is a key element of student success and the application of MUVEs to support synchronous communication and social interaction lends itself to increased student motivation to learn through this medium (Barab, Thomas, Dodge, Carteaux, \& Tuzun, 2005; Delucia, Francese, Passero \& Tortora, 2009). In describing the benefits of integrating SL into the social learning process, Smith and Barge describe SL as “...an open source environment that fosters observation, imitation and modeling behaviors. Residents are constantly learning from each other through interaction" (2009, p.443).

Unlike traditional classroom settings or more conventional learning methodologies, MUVEs offer unique learning platforms with at least four distinct features including (1) a 3D illustration space, (2) an avatar that visually represents the user, (3) interactive tools for communications in text, audio and symbolic formats (Dickey, 2005a) and (4) the "ability for a user to 'act' on the world" (Hew \& Cheung, 2008 , p. 34). In their review of research literature on virtual worlds in K-12 and higher education settings, Hew and Cheung (2008) found that these benefits of virtual world environments can impact "participants' affective domain, participants' learning outcomes, and participants' social interactions" (p. 9).

As described by Andreas et al. (2010), the elements critical to effective collaborative learning include: (1) discussion, (2) reciprocal teaching, (3) problem solving, (4) graphic information organizing, and (5) collaborative writing. MUVEs have the advantage of leveraging the Internet to bring these elements to thousands, even millions of users 
(Harmon, 2008) to provide various learning experiences, some of which can be very difficult to offer to students in the real world because of distance, time, cost, danger or impracticality (Chittaro \& Ranon, 2005). Often, EFL students in countries where English is not the official language are not given an opportunity to experience authentic social and cultural presences within their educational circumstances and MUVEs are able to bridge this gap within language instruction.

It is suggested that competence, both linguistic and pragmatic, is the knowledge developed and acquired through exposure and use of the target language (Kasper, 1997). A struggle for EFL teachers is finding ways to expose their students to the target language (TL) and developing learners' communicative ability in real-life situations. Unlike most of their ESL counterparts, many EFL students lack access to native speakers for authentic communication. As soon as they leave the classroom, they return to a world full of speakers of their own first language, leaving them with little opportunity to utilize what they learned during instruction. EFL teachers now urgently need a solution to increase exposure and use of the target knowledge both inside and outside of the classroom (Chen, 2005).

Learning merely the target linguistic knowledge cannot successfully engage learners into real-life communications in the target culture; they also need to acquire the target pragmatic competence, the capacity to incorporate cultural knowledge into language use and choose appropriate language in different sociocultural contexts (Bachman, 1990). Scholars and practitioners alike agree that communicative competence must successfully be demonstrated within true social contexts. By integrating such platforms as SL or other MUVEs into language learning, verbal communication skills within a social context can be fostered and reinforced (Shih, Lin \& Yang, 2007). The need for inte- grating technology into EFL learning and instruction is supported by extensive literature on Computer Assisted Language Learning (CALL) and Computer Mediated Communication $(\mathrm{CMC})$ and is strongly encouraged by the EFL community. A primary focus of CALL and $\mathrm{CMC}$ research (especially language learning at a distance) has been on the use of technologies for the development of literacy in a second or foreign language (Lam, 2000; Shei, 2005).

As evidenced through its use by more than 250 colleges and universities, Second Life, one of the most popular MUVEs, has become a valuable tool in promoting interactive and effective instruction and learning opportunities, allowing for collaboration and creativity in lessons via virtual classes, discussions, presentations, field trips and guest lectures (Diehl \& Prins, 2008). Some common advantages of SL compared to traditional EFL classrooms include: Mechanisms to promote effective and active learning (Beatty, 2004 as cited by Wang \& Braman, 2009), the ability to provide an environment for language and culture immersion with multiple interactive media and a rich sense of contexts for learning (Warburton, 2009), possibility to reduce students' tentativeness which may be present in "normal" classroom settings, and finally, a general sense of being more fun as compared to traditional methods of learning (especially with regard to digital natives).

As a teaching tool, SL aligns with the aforementioned need for the integration of technology put forth as a focus of CALL and CMC research. More specifically, in a study conducted by Yee, Bailenson, Urbanek, Change and Merget in SL, results showed that "our social interactions in online virtual environments, such as Second Life, are governed by the same social norms as social interactions in the physical world" (2007, p.119). In this respect, not only do MUVEs address the need for greater application of technology in EFL/ESL learning, but provide environments where so- 
cial interaction is commensurate with real life experience. Learning is no longer restrained in time and space; rather, by incorporating $\mathrm{CMC}$ and CALL in the EFL classroom, learners are offered opportunities to communicate and learn collaboratively with other teachers and learners across continents (Kern, 1996; Shield \& Weininger, 2004). Engaging EFL learners in these authentic social interactions not only exposes them to the target language, but also gives them authentic opportunities to practice what they have learned in the classroom (Blake, 2000; Campbell, 2004, Leh, 1999, Lightbown \& Spada, 1999).

Current literature also posits that MUVEs, when utilized with due diligence to thorough instructional preparation, appropriate application, and contingency planning, can play a successful role in the teaching and learning experience. Baker et al. (2009) provide specific suggestions to encourage positive results when using MUVEs in instruction and, although not specific to EFL/ESL learning, if integrated, can be instrumental in achieving the desired results of language learning in platforms such as SL. Included in their recommended "toolkit" are the following suggestions:

1. Define specific objectives and explain to students why the technology is appropriate for learning in the virtual environment.

2. As an instructor, become familiar with the technology and allow students the same opportunity before commencing an active lesson; engage other users of SL within the academic arena for support.

3. Prepare contingency plans in the event technology fails; continue lessons via email or other discussion tools and notify students of these plans at the start of the lesson.
4. Engage students by pairing them with partners and solicit their feedback on what is effective and ineffective from their perspective as learners.

5. Introduce the technology on a small scale with simple, preparatory exercises which allow students to acclimate; transition to more complex activities as students become comfortable with the application.

Due to its affordance to offer authentic and interactive language learning environments, SL is being used as an active medium for language learning and instruction. Much opportunity exists to expand upon current literature and research as to the efficacy of using MUVEs as an EFL learning tool as well as to provide more tangible resources specific to EFL instruction. Learning how to teach and facilitate EFL learning in SL will be a significant task for many EFL teachers in the future.

\section{Research Questions and Methodology}

This research explores student teachers' perspectives on teaching in an experimental EFL program in SL with the following two research questions:

1. What are the student teachers' perceptions of SL as an EFL learning platform and the SL_EFL Program as a whole?

2. What are the perceived problems and lessons learned by the student teachers in the SL_EFL Program?

To answer the research questions above, a case study approach (Krathwohl, 1998; McMillan \& Schumacher, 1997) was used to explore student teachers' perspectives on teaching EFL in Second Life. A case study, according to Creswell (2008), is an "in-depth exploration of a bounded system (e.g. activity, event, process, or individuals) based on an extensive data col- 
lection" (p. 464). Yin (2003) points out that a case study is appropriate when the case is a representative or typical one and for "learning of an unknown or poorly understood situation" (Leed \& Ormrod, 2010, 108). The case study approach is the most suitable methodology for this study because of the "flexibility and adoptability to a range of contexts, processes, people, and foci" (McMillan \& Schumacher, 1997, p. 394). These characteristics are needed for examining in depth the student teachers' perspective on the true application of SL for EFL/ESL learning: Teaching real EFL students in SL.

\subsection{Research Context and Participants}

The study was implemented online in SL with participants from an American state university and a Chinese provincial university. The American university is the Southeast's leading urban research institution in the USA. Its participants were eight graduate students with four majoring in ESL education and four majoring in Instructional Technology. This paper reports only the instructional experiences of those four graduate students majoring in ESL education.

The study participants in the American university were recruited through program email listserves with the only promised incentive of presenting research results in a national conference with researchers. These self-motivated participants were interested in learning more about teaching ESL in SL. Among them, two female participants were in their early twenties teaching English part-time at local schools. One male participant in his early twenties was a full-time graduate student and the other was in his forties switching his career from banking to education while teaching on probation at a local elementary school. They had very limited experiences in terms of classroom instruction and none of them had taught online in a virtual learning environment like SL. Among them, one male student teacher had been exposed to SL early in 2007 but had otherwise never used it until this study, and the other student teachers used SL for the first time for this study. These American participants served as teachers in this experimental EFL Program in SL (SL_EFL Program) and are termed "student teachers" in this paper.

The Chinese university is a comprehensive provincial university in east China with twenty academic colleges and schools. Its participants were 29 full-time sophomores majoring in English in its School of Foreign Languages. They were students in this SL_EFL Program which was a required supplementary instruction to their regular listening and speaking course.

\subsection{Procedure and Instructional Tasks}

The SL EFL Program provided the student teachers with opportunities to teach and interact with the Chinese EFL students synchronously online in SL. The study took place over a six-week period. Before the start of the program, the student teachers participated in a one-hour workshop on basic uses of SL. Their instructional tasks/lessons for each week were (a) two one-hour sessions in SL, (b) reflective writing on their instructional experiences in SL, and (c) preparation for instructional activities in SL for the subsequent week. The instructional procedures and activity contents were designed by the researchers. A website was created to give detailed instructions outlining procedures to complete the lessons for each week, together with instructional reference materials on the culture relevant to the topic of the week. The instructional activities for student teachers in SL included leading and facilitating small group discussions, guiding virtual tours with Chinese students, conducting one-on-one interviews with the Chinese students and offering lecture presentations. Table 1 summarizes instructional topics covered and implementation procedures of the SL_EFL Program. 
Table 1: Instructional Topics and Procedure in the SL_EFL Program

\begin{tabular}{|c|c|c|}
\hline Week & Topic & General Instructional Procedure \& Tasks \\
\hline 1 & University Student Life & 1. Start HyperCam screen recorder. \\
\hline 2 & Career Preparation & 2. Log into Second Life and teleport yourself to the class \\
\hline 3 & $\begin{array}{l}\text { Holiday Celebrations: } \\
\text { Thanksgiving }\end{array}$ & 3. Introduce yourself and learning tasks for the Chinese \\
\hline 4 & $\begin{array}{l}\text { Traditions and Celebra- } \\
\text { tion of Spring Festival } \\
\text { in China }\end{array}$ & $\begin{array}{l}\text { 4. Complete instructional tasks in Second Life. } \\
\text { 5. When you finish, stop recording and exit HyperCam. } \\
\text { 6. Copy the recorded video file on a flash drive and give to }\end{array}$ \\
\hline 5 & People and Pets & research assistants. \\
\hline 6 & $\begin{array}{l}\text { Presentation: What I } \\
\text { have learned in Second } \\
\text { Life }\end{array}$ & $\begin{array}{l}\text { 7. Check the blog site to comment on what students' } \\
\text { posting. } \\
\text { 8. Read instructional materials and prepare for the next } \\
\text { session. }\end{array}$ \\
\hline
\end{tabular}

Two student teachers taught the SL_EFL Program from faculty offices on the university campus while the other two taught the SL_EFL Program from home. All the student teachers had technical support in SL provided by a graduate student of Instructional Technology when they were teaching in SL. At the same time, two Chinese technical support persons were present in the media lab assisting their Chinese students who might have technical issues during the sessions. At the end of the SL_EFL Program, student teachers took the post-study survey and participated in a focus group interview with researchers; two students also participated in individual interviews followed by the focus group interview.

\subsection{Instruments, Data Collection and Analysis}

Data collection methods included (a) post study surveys, (b) one-on-one and focus group interviews and (c) documentation review (e.g. student teachers' reflective paper on their instructional experiences in the SL_EFL Program).

The instruments (survey and interview questions and protocol) were revised accord- ing to the feedback received from participants in the previous year by two professors in the USA and three professors in China. These professors were experts in both EFL and instructional technology and design. Their review efforts validated the instruments used in this study. The survey aimed at soliciting information regarding student teachers' perceptions of SL as an EFL learning platform and the SL_EFL Program.

A focus group interview was conducted after the SL_EFL Program. The interview was in semi-structured format with prepared interview questions and questions which came up during the actual interview. Again, the questions asked were to reveal student teachers' perception of SL as an EFL learning platform and the SL_EFL Program as a whole. The interview was recorded and then transcribed into text for analysis. To triangulate the findings, the research team also reviewed student teachers' reflective papers and conducted two follow-up interviews to confirm initial findings. All the data (e.g. reflective papers and interview transcripts) collected was categorized, coded and analyzed by two graduate students and an assistant professor of research in the USA. 


\section{Results}

The analysis of the study results and discussions attempt to answer the research questions posted above. The data analysis results can be summarized as follows.

\subsection{Student Teachers' Perception of SL as an EFL Learning Platform}

Student teachers held positive reactions to SL as an EFL learning platform with distinct perceived advantages for EFL teachers. First, they generally agreed on the conceptual benefits of using SL to help ESL/EFL students become more comfortable speaking English and describe that "here they have the advantage of speaking with people like me who do not speak Chinese and so if they wanted to communicate with me, they would have to be speaking English". Second Life allows the students in China the experience of living the language through conversing with native speakers. Second Life also affords more robust avenues for conversation through the use of multiple avatars and permits more than two people to be involved in the conversations; it provides an environment whereby "in a single big room, you could break into discussion groups without everybody hearing everybody". Unlike using a telephone and other web-conference tools, the participants can come together to explore new places within SL as a group. Connecting native with nonnative speakers has demonstrated effectiveness for providing realistic conversations in a setting which could be supported by supplemental visual materials and allows Chinese students an incredible opportunity to learn about not only the language, but also culture from people who actually grew up in it. One of the student teachers clearly described this in the interview as follows:

The greatest advantage for, in EFL or ESL classes, it gives non-native speakers the opportunity to speak with native speakers. A lot of them have for example; in China they have Chinese learners who have learned English as a second language teaching them. And they never have contact with a native speaker. And for that, Second Life is effective.

This perceived benefit of SL for EFL learning and instruction was also recorded in their reflection papers. Lily, a student teacher, described how "Second Life intertwines with real life using technology allowing the players, in this case students, to feel as though they are there in person" and "opens the doors for us to connect with ESL students locally, nationally, and internationally."

Additionally, all student teachers enjoyed the interactive nature of SL that allows them to teach English online by not just speaking into the microphone but by acting, performing, and collaborating in English with their students. One female student teacher related one of her favorite lessons as a virtual trip to the zoo "because we could incorporate the setting with the conversation" which afforded a more dynamic learning experience. Reaching a level of student engagement and overcoming the anxiety of unfamiliar subject matter is crucial not only in EFL learning, but any educational experience.

As an EFL learning platform, its unpredictability of technology comprised the majority of issues whether it was sound, ambient noise, or connectivity. The student teachers were in accord that the time and energy spent trying to overcome technical difficulty was a major impediment to the productivity of the study. For example, one student teacher describes that "trying to figure out how to be able to keep them (the Chinese students) engaged while I was figuring out what was going on I think was something interesting that I would not have encountered where there are not as many barriers". 
On the whole, the student teachers felt that SL was a wonderful new platform for EFL learning and instruction. More thorough guided and self-led explorations of SL, technical training, and troubleshooting prior to the SL_EFL Program would certainly have benefitted both the student teachers and their EFL students in China.

\subsection{Student Teachers' Perceptions of the $S L_{-}$ EFL Program}

All student teachers believed that the SL_ EFL Program provided them with precious opportunities to practice EFL instruction in a real learning environment with authentic students and meaningful interactions. The SL_EFL Program bridges not only the geographic distance but also that of language and culture. Through this program, the student teachers developed social bonds with their students as they do in the real classroom. This reoccurring theme was illustrated by a student teacher who wrote in the reflection paper that "there were moments when we would all laugh together that I would actually get the chills because I realized that technology and the Internet were allowing me to sit and learn from a group of Chinese students on the opposite side of the world, and that we actually had a lot in common".

The SL_EFL Program helped the student teachers better understand pedagogical strategies for EFL learning and instruction and applications of meaningful interactions in EFL instruction. For example, when discussing the Spring Festival in China, the Chinese students were encouraged to interact in English with a subject they were familiar with while simultaneously building vocabulary and strengthening conversational skills. One student teacher described the positive result of this specific lesson as follows:

The nicest thing was in fact talking about the Spring Festival. Obviously, in addition to the prepared material which they wanted to read to me or recite, they knew a lot about the Spring Festival because it's a very important festival. And the two students I had at that time were from two different regions of China. And the practices of Spring Festival vary whether you're from the north or south apparently. And so... as they began to explain things, they began to disagree with each other. They had different things to tell me and that was really the, sort of the best thing that happened was to get you know, off the prepared material.

To enhance English listening and speaking skills, it was very important for student teachers to create a learning environment which encouraged a comfort level to speak freely and comfortably. The SL_EFL Program did a very nice job in that many of the tasks in SL emerged so that both student teachers and their Chinese students were learning from each other. The SL learning environment bridged the distance between teachers and students and easily engaged students in meaningful interactions with their teachers and peers. As described by one female student teacher:

So, experiencing things that would never really happen in the real classroom but still going with it and then laughing. So because of that we laughed, and laughing in Second Life helped some, for some reason much better than it did in the real classroom.

Even with technological, language and pedagogical challenges, the SL_EFL Program has cultivated positive experiences of EFL instruction for these student teachers in addition to those social bonds with their Chinese students developed from the Program. 


\subsection{Perceived Problems by the Studet Teachers Teaching in the SL_EFL program}

The technical problems which occurred in the SL_EFL Program such as frozen screens or delayed audio can be easily solved by upgrading the lab computers and connecting cables. However, the pedagogical problems such as class management remain one of the most challenging aspects of the program according to the student teachers.

Due to interactive nature of the instruction in SL, students might walk or even fly away, at any moment from the discussion group or instructional site in SL, which rarely or would not happen in a real classroom. The student teachers felt it challenging to deal with this situation in their instructions in SL. In addition, it was very easy for students to either stray away from the given topic or to not speak at all. A female student teacher made an excellent point of indicating that additional instructional training on classroom management for these student teachers would be necessary for them to teach effectively in a learning platform such as SL.

Usually, a good teacher can get a feel for his/her classroom by looking into their student's eyes or watching for facial expressions or body movement. However, teaching EFL in SL, this communication cue is lacking because the teacher can only see the avatar, which, for the majority of the time, is emotionless. On the one hand, the quiet time could be students processing their thoughts in English before feeling comfortable enough to speak; on the other hand, the student simply may not know the answer and is waiting for the instructor to solve the puzzle for them. This observation was made by one of the student teachers when he described a students' tentativeness during his session:

Silence is very strange, when it comes to language, you know, like, when some- one's silent, they could be thinking.... and you have to, and what's weird is when you're dealing with someone who can't really produce the language, you have to give them time to percolate like that. And there's a real art to knowing OK, when do I jump in, and I'm not a pro at it and not being able to see them kind of made it harder...

Both of these situations validate the need for additional classroom management guidelines for the student teachers. One area of need relates to different social customs between cultures. Because social mores vary from culture to culture, it is important that student teachers be familiarized with generally accepted social customs of their students so as not to offend or alienate. As a general rule, student teachers should be provided with at least cursory classroom management techniques. This need is demonstrated through the remark that "I knew that the study didn't require you to be a teacher, just a native speaker and so I wasn't really thinking exactly about managing a class as I was being a participant". This balance between classroom management and understanding customs was discussed in the post-study interview by one of the male student teachers:

Classroom turn taking is always important and if the customs are different, which they typically would be across cultures, we would like to get some practice doing that... When you think about it, you think you're going to wait for the other people to stop talking and take your next turn, but in fact, in real life, you speak over the end of other people as you sense their transitioning. And you're signaling the end of things by an up down [intonation] and people recognize that and move on so that's how you can guess when I'm done talking. So, I did think that some help with classroom management skills and to be 
more mindful of that would've been more helpful for me.

Regardless of the situation, it is evident that in SL, student teachers must be prepared to steer both the nature of the conversation as well as prompt students' ideas and conversation when necessary. There was general agreement that many of the challenges could have been avoided had they had more background information on the program objectives and had a full curriculum for the six weeks been developed or disclosed beforehand.

\section{Discussion}

Before the discussion of the study implications, some limitations of the study need to be mentioned. Due to practical constraints, the study was conducted among a fairly small group of the student students. Though the $\mathrm{SL}_{-}$ EFL Program lasted for six weeks, the actual teaching hours in SL was limited (just a little over 12). The experiences of teaching in SL, therefore, were not long enough to offer stable and generalizable concepts but anecdotal snapshots regarding EFL learning and instruction in SL. With these limitations, we want to remind the readers of the extent to which the study's results can be generalized.

The study results reveal not only the student teachers' perceptions of SL and the SL_ EFL Program but also offer implications for and suggestions to the future program design to enhance the use of SL for EFL learning and instruction. The most obvious enhancement would be to reduce the technical impediments in using SL. Student teachers generally agreed in that "as far as keeping it basic for people who are not as knowledgeable in the field of technology, especially a lot of the teachers at the school, when you get too confused by too many things going on at one time, you lose the focus of what's important in teaching". The implication of this statement is that to ensure greater success in the program, either more technological support or training must be provided for effective instruction in SL. This is in accordance with the literature that indicates a steep learning curve for using SL for learning and instruction (Baker, Wentz \& Woods, 2009; Cheal, 2009; Taylor \& Chyung, 2008).

Course design and pedagogy were among the main themes discussed by the student teachers. Teaching is challenging to new teachers and teaching in MUVEs makes it even more difficult for them. To help the student teachers teaching in similar EFL programs, a well prepared set of instructional guidelines, expectations, and lesson plans familiar to both student teachers and students will certainly improve the delivery of content and end results of the program. The student teachers reiterated numerous times the need for clearly stated objectives, access to resources that their students were using, and the integration of resources within Second Life to complement the speaking exercises. In this sense, improvement of design and implementation at the program level would enhance EFL instruction and facilitate EFL learning in SL.

Though the focus of this paper is on student teaching in SL, the use of supplemental resources such as access to a course blog is highly encouraged to help student teachers connect with students and improve overall learning and instructional performance in the SL_EFL Program. The use of a blog site is an incredible idea; as described by one of the student teachers: "the blog was really going to be, per your design, a crucial element in bonding the teachers with the students because I would've expected their proficiency in writing to be greater than in listening and speaking and this would of, you know, been a chance for us to establish greater rapport ..." The use of a blog would give teachers and students a chance to reflect about the sessions, get to know each other even more and 
allow for the integration of writing and reading into the program. Giving students every opportunity to practice in each language domain (listening, speaking, reading, and writing) is extremely important to their language learning process and provides even more validity to implementing an SL program into an EFL program.

This study is about American student teachers teaching in the SL_EFL Program with the Chinese EFL students. It will be interesting to see the collaboration between American student teachers working collaboratively with English professors in China. As posited by one of the student teachers that "there are lots of teachers of English in China and if they were working with teachers of English here, the collaboration is not working with actual students but working with their teachers." $\mathrm{He}$ adds that "you could separately be developing in Second Life the stuff you want because there is now a shared interest in developing it" as a learning tool. The idea of collaboration between instructors from both native and nonnative learning perspectives provides compelling thought for the future possibilities of using SL for EFL instruction.

\section{Conclusion}

This paper reports a case study on student teachers' perceptions of SL as an EFL learning platform and an EFL learning program in SL. Based on the results, we discussed implications and suggestions for designing, implementing and enhancing future EFL programs in SL. It was exciting and encouraging to see the overall positive perceptions of the student teachers on both SL as an EFL learning platform and the SL_EFL Program as a whole. It was believed that the student teachers took a lot from this opportunity and felt confident about its future potential. Second Life is clearly a platform with much to offer to EFL/ ESL instruction. With the addition of technol- ogy support, clearly defined objectives and curriculum, and supporting resources such as blogs and lesson plans, SL is poised to become a great supplement to EFL learning and instruction. In the exact words of one teacher, "I see so much potential, it's so exciting."

\section{References}

American Council of the Teaching of Foreign Language (ACTFL)(2011). National standards for foreign language education. Retrieved on September 21, 2011 from http://www.actfl.org/i4a/pages/index. $\mathrm{cfm}$ ?pageid=3392\#standards

Andreas, K., Tsiatsos, T., Terzidou, T., \& Pomportsis, A. (2010). Fostering learning in Second Life: Metaphors and affordances. Computers \& Education, 55(2010), 603-615.

$\mathrm{Au}, \mathrm{W}$. J. (2008). The making of Second Life: Notes from the new world. NY: Harper Collins Publisher.

Bachman, L. (1990). Fundamental considerations in language testing. Oxford, UK: Oxford University Press.

Baker, S., Wentz, R., \& Woods, M. (2009). Using Virtual Worlds in Education: Second Life as an Educational Tool. Teaching of Psychology, 36, 59-64.

Barab, S., Thomas, M., Dodge, T., Carteaux, R., \& Tuzun, H. (2005). Making learning fun: Quest Atlantis, a game without guns. Educational Technology Research \& Development, 53(1), 86-107.

Belcher, D. \& Hirvela, A. (Eds.). (2008). The oral-literate connection: Perspectives on L2 speaking, writing, and other media interactions. Ann Arbor, MI: University of Michigan Press.

Blasing, M. T. (2010). Second language in Second Life: Exploring interaction, identify and pedagogical practice in a virtual world. Slavic and East European Journal 54(1), 96-117. 
Blake, R. (2000). Computer mediated communication: A window on L2 Spanish interlanguage. Language Learning and Technology. 4(1) $120-136$.

Bruckman, A. (1997). MOOSE Crossing: Construction, community, and learning in a networked virtual world for kids. Unpublished $\mathrm{PhD}$, MIT.

Burgess, L., Slate, J., Rojas-LeBoeuf, A., LaPrairie, K. (2009). Teaching and learning in Second Life: Using the Community of Inquiry (CoI) model to support online instruction with graduate students in instructional technology. Internet and Higher Education, 3(2010), 84-88.

Campbell, A.P. (2004). Using lifejournal for authentic communication in EFL classes. The Internet TESL Journal 10(9). Retrieved on September 21, 2011 from http://iteslj. org/Techniques/Campbell-LiveJournal/

Cheal, C. (2009). Student perception of a course taught in Second Life. Innovate: Journal of Online Education, 5(5). Retrieved on September 23, 2011 from http:// innovateonline.info/pdf/vol5_issue 5/Student_Perceptions_of_a_Course_Taught_ in_Second_Life.pdf

Chen, Y.H., (2005). Computer mediated communication: The use of CMC to develop EFLlearners' communicative competence. Asian EFL Journal, (7)1. Retrieved on September 21, 2011 from http://www.asian-ed-journal. com/march_05_yhc.php

Chittaro, L., Ieronutti, L., \& Ranon, R. (2004). Navigating 3D Virtual Environments byFollowing Embodied Agents: a Proposal and its Informal Evaluation on a VirtualMuseum Application. PsychNology Journal (Special issue onHuman-ComputerInteraction), 2(1), 24-42.

Creswell, J. W. (2008). Educational Research: Planning, conducting, and evaluating quantitative and qualitative research (3rd ed.). Upper Saddle River, NJ: Pearson Education Inc.
Delucia, A., Francese, R., Passero, I., \& Tortora, G. (2009). Development and evaluation of a virtual campus on Second Life: The case of SecondDMI. Computers \& Education, 52 (1), 220-233.

Dickey, M. D. (in press). The pragmatics of virtual words for L-12 educators: Investigating the affordances and constraints of Active Worlds and Second Life with K-12 in-service teachers. Educational Technology Research \& Development.

Diehl, W. C., \& Prins, E. (2008). Unintended outcomes in Second Life: Intercultural literacy and cultural identity in a virtual world. Language and Intercultural Communication, 8(2), 17.

Dillenbourg, P., Schneider,D., Synteta,V., (2002) "Virtual Learning Environments", Proceedings of the 3rd congress on information and communication technologies in education, Rhodes, Kastaniotis Editions, Greece, 3-18.

Erlandson, B. E., Nelson, B. C., Wilhelmina, C. S. (2010). Collaboration modality, cognitive load, and science inquiry learning in virtual inquiry environments. Educational Technology Research \& Development, 58(6), 693-710.

Harmon, S. W. (2008). A theoretical basis for learning in massive multiplayer virtual worlds. Journal of Educational Technology Development and Exchange, 1(1), 29-40

Hew, K. \& Cheung, W. (2008). Use of three-dimensional (3-D) immersive virtual worlds in K-12 and higher education settings: a review of the research. British Journal of Educational Technology,39, 6, 959-1148.

Jarmon, L., Traphagan, T., Mayrath, M., \& Trivedi, A. (2008). Exploration of learning in Second Life in an interdisciplinary communication course. Paper presentation at American Educational Research Association (AERA). New York, New York.

Kasper, G. (1997). Can pragmatic competence be taught? (NetWork \#6) [HTML docu- 
ment]. Honolulu: University of Hawai'I, Second Language Teaching \& Curriculum Center. Retrieved September 21, 2011 from the World Wide Web: http://www. nflrc.hawaii.edu/NetWorks/NW06/

Kern, R. (1996). Computer-mediated communication: Using e-mail exchanges to explore personal histories in two cultures. In M. Warschauer (Ed.), Telecollaboration in foreign language learning (105-119). Honolulu, HI: Second Language and Curriculum Centre.

Krathwohl, D. R. (1998). Methods of educational and social science research (2nd ed.). New York: Addison Wesley Longman, Inc.

Lam, E. W. S. (2000). L2 literacy and the design of the self: a case study of a teenager writing on the Internet. TESOL Quarterly, 34(3), 457-481.

Lead, P. D. \& Ormrod, J. E. (2010) Practical Research Planning and Design ( $9^{\text {th }}$ ed). Boston, MA. Pearson Education, Inc.

Lee, J. (2000). Tasks and communicating in language classrooms. Boston: McGraw-Hill.

Leh, A.S.C. (1999). Computer mediated communication and foreign language learning via electronic mail. Interactive Multimedia Electronic Journal of Computer-Enhanced Learning. Retrieved on September 21, 2011 from http://imej.wfu.edu/articles/1999/2/08/index.asp

Li, M. C., Cheung, S. F. \& Kau, S. M. (1979). Competitive and cooperative behavior of Chinese children in Taiwan and Hong Kong. Acta Psychologica Taiwanica, 21, 27-33.

Li, Z. \& Mao, Y. (2008). The study of educational potentials of Second Life and its implications to distance education. Modern Educational Technology, 18(1), 81-83.

Lightbown, P.M. \& Spada, N. (2006). How Languages are Learned (3 ${ }^{\text {rd }}$ ed.) .Oxford, UK: Oxford University Press.

Lim, C., Nonis, D., \& Hedberg, J. (2006). Gaming in a 3D multiuser virtual environment: Engaging students in science lessons.
British Journal of Educational Technology, 37(2), 211-231.

McMillan, J. H., \& Schumacher, S. (1997). Research in education: A conceptual introduction (4th ed.). New York: Longman, Inc.

Nelson, B. \& Ketelhut, D.J. (2007). Scientific inquiry in educational multi-user virtual environments. Educational Psychology Review, 19(3), 265-283.

Richardson, J.C. \& Swan, K. (2003). Examining social presence in online courses in relation to students' perceived learning and satisfaction. Journal of Asynchronous Learning Networks, 7(1).

Riedl, R.E., Tashner, J.H., \& Bronack, S.C. (2003). A virtual world initiative: Assumptions about teaching and learning. International Conference on New Educational Environments. Lucerne, Switzerland.

Second Life. Retrieved August 28, 2009, from http://www.secondlife.com/

Shei, C. (2005). Integrating content learning and ESL writing in a translation commentary writing aid. Computer Assisted Language Learning, 18(1-2), 33-48.

Shield, L. \& Weininger, M.J. (2004). Collaboration in a virtual world: Groupwork and the distance language learner. In R. Debski \& M. Levy (Eds.) World CALL: Global Perspectives on Computer-assisted Language Learning. The Netherlands:Swets \& Zeitlinger Publishers.

Shih, Y., Lin, Y. \& Yang. M.T. (2007). The development of an online virtual English classroom: VEC3D, Journal of Information Technology and Applications, Special Issue on Computer and Network Technologies in Education, 2 (2), issue 2.

Smith, M. \& Berge, Z.L. (2009). Social learning theor in Second Life. Journal of Online Learning and Teaching 5(2), 439-445.

Squire, K. \& Jenkins, H. (2004). Harnessing the power of games in education. Insight 3(1), 5-33.

Taylor, C. K. \& Chyung, S. Y.(2008). Would 
you adopt Second Life as a training and development tool? Performance Improvement 47(8), 17-25.

Wang, Y. \& Braman, J. (2009) Extending the Classroom through Second Life. Journal of Information Systems Education (Special edition: Impacts of Web 2.0 and Virtual World Technologies on IS Education) 20(2), 235-247.

Warburton, S.(2009). Second Life in higher education: Assessing the potential for and the barriers to deploying virtual worlds in learning and teaching. British Journal of Educational Technology. 40(3), 414-426.

Wickens, C.D. (1992). Virtual reality and education. Proceedings of the 1992 IEEE International Conference on Systems, Man and Cybernetics, vol. 1, 842-847.

Yee, N., Bailenson, J., Urbanek, M., Chang, F., Merget, D. (2007). The Unbearable Likeness of Being Digital: The Persistence of Nonverbal Social Norms in Online Virtual Environments. Cyber Psychology \& Behavior, 10(1), 115-121.

\section{Contact the Authors}

Charles Xiaoxue Wang, Ph.D.

Florida Gulf Coast University

Email: xxwang@fgcu.edu

Mary L. McDowell Lefaiver

Florida Gulf Coast University

Email:mmlefaiv@eagle.fgcu.edu

\section{Qi Wang}

Georgia State University

Email: qwang10@student.gsu.edu

\section{Christy Hunt}

Dekalb County School District

Email: christy_hunt@fc.dekalb.k12.ga.us 